\title{
A Trainee's Approach for Effective Operating Room Learning
}

\author{
Dr. Hassan Tahir \\ Dr. Madiha Haroon \\ Dr. Usman Ali Mobin
}

Surgical Trainee at Department of General Surgery,

Liaquat National Hospital, Karachi

\section{Dr. Faisal Siddiqi}

Associate Professor, Department of General Surgery,

Liaquat National Hospital, Karachi

\section{Dr. Mirza Arshad Beg}

Assistant Professor, Department of General Surgery,

Liaquat National Hospital, Karachi

Doi:10.19044/esj.2021.v17n10p290

Submitted: 20 November 2020

Accepted: 12 February 2021

Published: 31 March 2021
Copyright 2021 Author(s)

Under Creative Commons BY-NC-ND

4.0 OPEN ACCESS

Cite As:

Tahir H., Haroon M., Mobin U.A., Siddiqi F. \& Beg M.A. (2021). A Trainee's Approach for Effective Operating Room Learning. European Scientific Journal, ESJ, 17(10), 290.

https://doi.org/10.19044/esj.2021.v17n10p290

\section{Abstract}

Introduction: Surgical training has gone through a paradigm shift in recent years. The trends have shifted from an apprenticeship model to a new era of self-teaching and an attitude-driven learning. In this study, we aim to comprehensively investigate the knowledge and attitude pertaining to the perception of preparation required for the operating room and how the residents prepare themselves for it. Method: A quantitative study was conducted via predefined questionnaire. Surgical residents at a single tertiary care institution were asked to complete the survey via Google forms that was distributed by means of email to residents of the general surgery department. Inclusion and exclusion criteria were defined. Results: Forty surgical residents opted to participate in the survey. The majority of the residents had a similar perception of operating room preparation. The most prominent theme that emerged following the discussion was that the residents learned through trial and error, and advice solicited from co-residents, which in the majority 
of the cases, were senior level resident. The resources defined by the residents were similar among majority and factors that affected their preparation were variable. An important aspect highlighted through the discussion was that the level of postgraduate training affected the preparation done by residents in order to better perform in operation theatres. Conclusion: Knowledge and attitude regarding operating room preparation was quite similar among the surgical residents. They varied in their practice for preparation.

Keywords: Operating room preparation, knowledge attitude and practice, training, medical students

\section{Introduction}

During recent two decades, surgical training has undergone a paradigm shift. Previously, surgical training was done in a traditional manner by one of the faculty teaching clinical and practical skills to the surgical residents (Goldwag \& Jung, 2020). This has shifted to a training model fashioned on the pillars of basic knowledge, the ongoing researches, and patients' specific concerns (Evans \& Schenarts, 2016). During recent time's increased patient flow and the number of surgeries being performed, the learning imparted to the residents has narrowed down to dynamic coaching in the operation room. This has raised concerns that the trainees are not prepared to practice and perform procedures independently. According to The American College of Surgeons Committee on Residency Training Survey, around 57\% of the Program Directors were worried about the patient quality care by their residents moving towards autonomous practice (Damewood et al., 2017). Thirty percent of surgical trainees were also worried about their preparedness to practice autonomously after completion of their training (Yeo et al., 2019). Improvements in educational resources and continuous introduction of new and innovative technologies have brought up a new shift in surgical training (Glass et al., 2015). A number of studies have been conducted on incorporation of technology in medical education that may aid in filling the gaps in training. A pilot study conducted at the University of Virginia showed that the incorporation of the use of iPad may increase the efficiency of residents in clinical and administrative matters along with the provision of good opportunities for their educational needs (Lobo et al., 2013). Another new innovation is the use of simulations that has been introduced into medical education and training of residents. For provision of such facilities, training institutes are designing and building skill labs consisting of hands on skills stations, virtual reality trainers, and computer-based programs (Pugh et al., 2017). Such simulation-based training has brought an improvement in surgical skills with a great success (Seymour et al., 2002; Scott et al., 2008; Holcomb et al., 2002; Sturm et al., 2008). Another development is the availability of a 
web-based SCORE (Surgical Council on Resident Education) curriculum which has been designed by the six US-based association, the purpose of which is to enhance the resident education and to assess their skills (Bell, 2007).

While these developments are encouraging on one hand, these demand an extra hour out of the operating room and clinical hours to practice and master these skills on the other hand (Goldwag \& Jung, 2020; Glass et al., 2015).

The aim of the study is to look into ways by which residents prepare for operating room, assess the knowledge of residents pertaining to the procedures, and utilize resources to build themselves and to know what challenges they face.

During the course of clinical training, preparation for operating room has been of paramount importance but no clear methodology has been designed or defined for resident to follow. The main objective of this study is to delineate a scientific approach that can be simulated for residents to match.

\section{Materials and Methods} committee.

Prior to the collection of data, the study was approved by ethical review

The survey form was designed using the themes mentioned by Goldwag and Jung in the study which was accepted in the American Journal of Surgery in December 2019. The themes mentioned were (1) All participants similarly defined preparation, (2) Residents learned through trial and error and co-residents, (3) Factors impacting preparation were time, attending, autonomy, case complexity, and difficulty finding resources, (4) Resource use varied, (5) PGY level impacted preparation and, (6) Optimal resources were high yield.

The survey forms were sent to the surgical residents working at the Department of General Surgery via Google forms. All forms were distributed via emails to the residents. A total of 58 residents were sent the forms, out of which 40 responses were recorded. The residents were given a period of 30 days to complete the form, from $1^{\text {st }}$ July 2020 to $31^{\text {st }}$ July 2020. After the stipulated period of time, no responses were accepted. All residents who responded to the questionnaire, and were actively undergoing surgical training, were included in the study. Those who failed to respond were excluded. The survey form consisted of 26 questions regarding the preparation for operating room excluding the demographic data of the residents. These questions were concluded into 9 topics keeping in view the themes and sub themes used by Goldwag and Jung (2020).

Residents who participated in the study were divided into junior and senior level residents. Junior level constituted of Post graduate year 1 and Post graduate year 2, whereas senior level residents were Post graduate year 3 to 
Post graduate year 5. There were 8 Post graduate year 1, 12 Post graduate year, 7 Post graduate year 3, 9 Post graduate year 4, and 4 Post graduate year 5 .

The responses were entered into Microsoft excel and were analyzed with the help of a researcher.

\section{Results}

Nine themes emerged to include: 1) Operating room (OR) preparation definition, 2) Preparation list for the operating room, 3) Factors affecting operating room preparation, 4) Specific resource use, 5) Differences in progressive preparation, 6) Preparation/study of the operating room list, 7) Guide to preparation, 8) Teaching colleagues aids in preparation and, 9) Optimal resource. These themes were sub divided into 26 questions (Appendix $1)$.

1 Regarding Definition of Operating Room Preparation

The majority of the residents were well-disposed in regard to the definition of operating room preparation. Thus, they were in agreement that the patient history, patho-physiology of the disease, surgical anatomy \& indications to operate, procedural steps, and knowing the complications are important topics to be covered while preparing for an OR case.

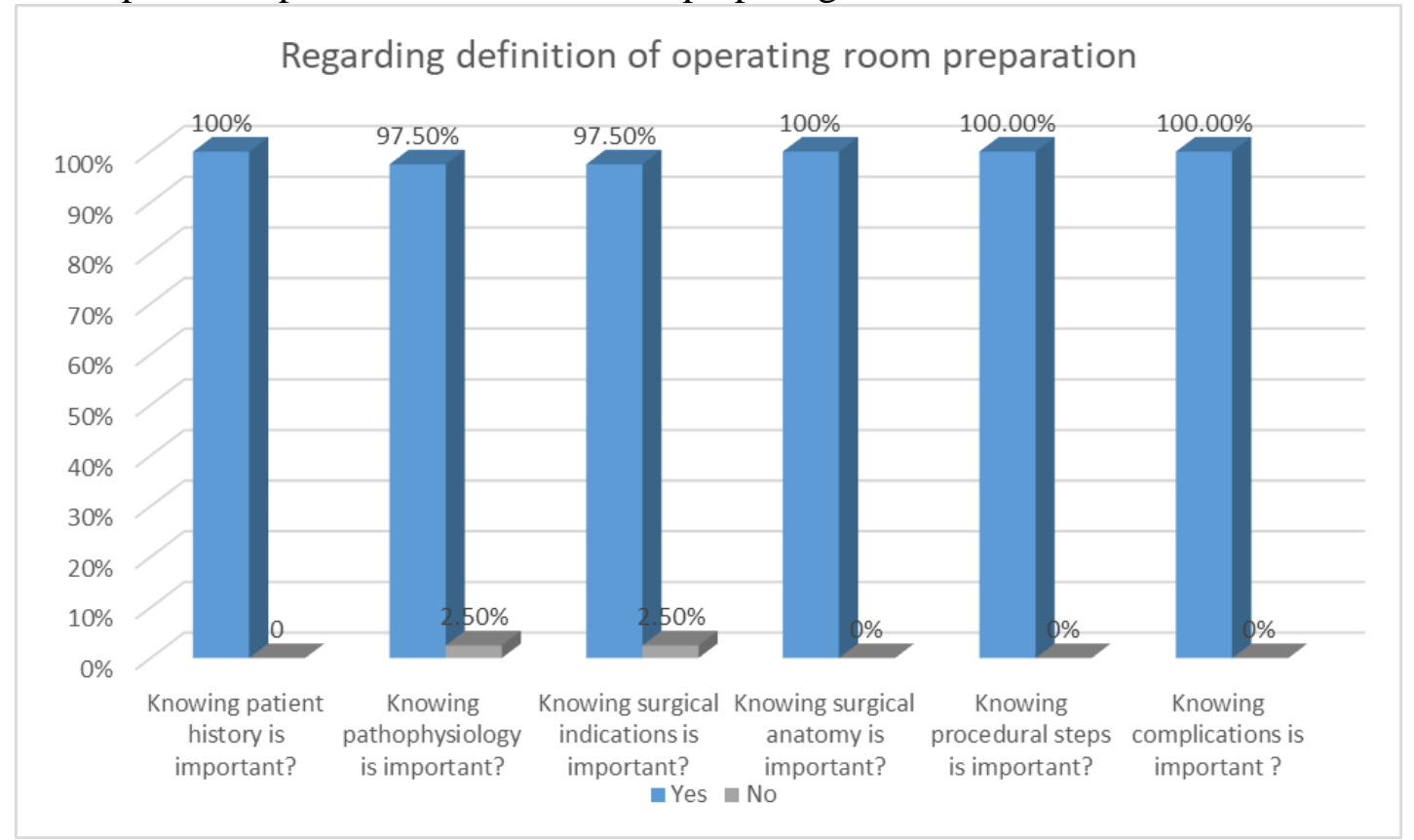

Figure 1. Regarding definition of operating room preparation 


\section{$2 \quad$ How do you prepare for the Operating Room List?}

When residents were asked about how they prepare for an OR list, they had differing views with a portion of the residents mentioning that they learned this during the undergraduate level when they were medical students. This is with $85 \%$ having the view that their preparation had improved over time as they have progressed in their residency. An assessment of improvement was evaluated by a better understanding of the procedural steps by the residents, and the residents performed more procedures when better informed.

Another theme that emerged was that a majority of the residents stated that their preparation has improved through trial \& error with foremost advice of a co-resident.

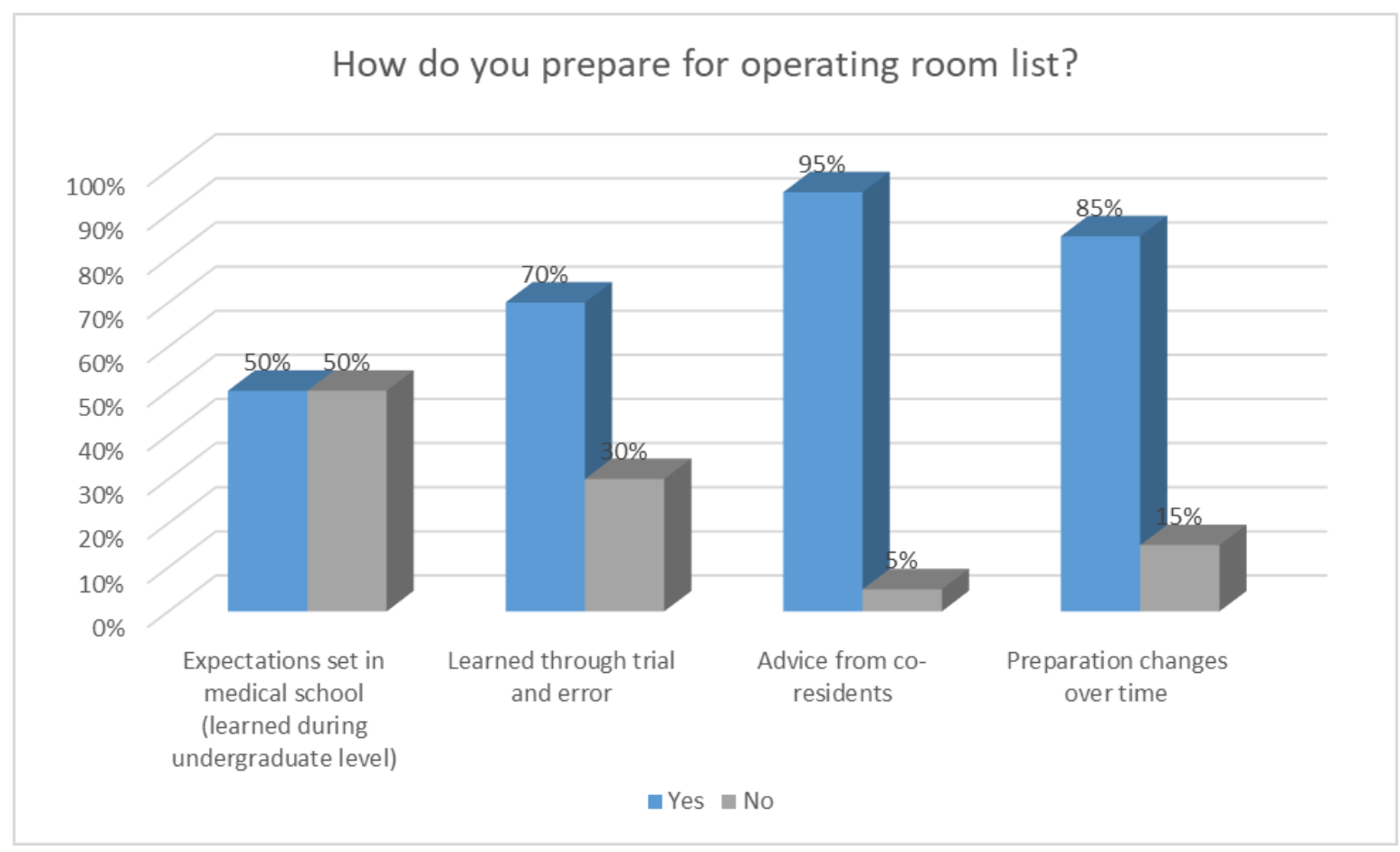

Figure 2. How do you prepare for the operating room list?

\section{Factors Affecting Operating Room Preparation}

In the current era of surgical training, not all training is limited to the confines of an OR, but part of the training is outside the OR. Therefore, the availability of time is a major factor affecting their preparation. Along with it, case complexity and expected autonomy in the case were prime factors observed to be affecting the preparedness for OR list/case.

Another aspect observed was as to whom was operating the case, whether it was the attending, senior registrar or senior resident leading the 
case. This was found to influence the preparation with no differences among particular PGY levels.

However, a factor which was found to be predominantly visible among females or married surgical trainees was the challenge of maintaining a balance between the profession and their personal lives. Easy availability and utilization of resources remained a matter of dispute between the trainees.

\section{Factors affecting operating room preparation}

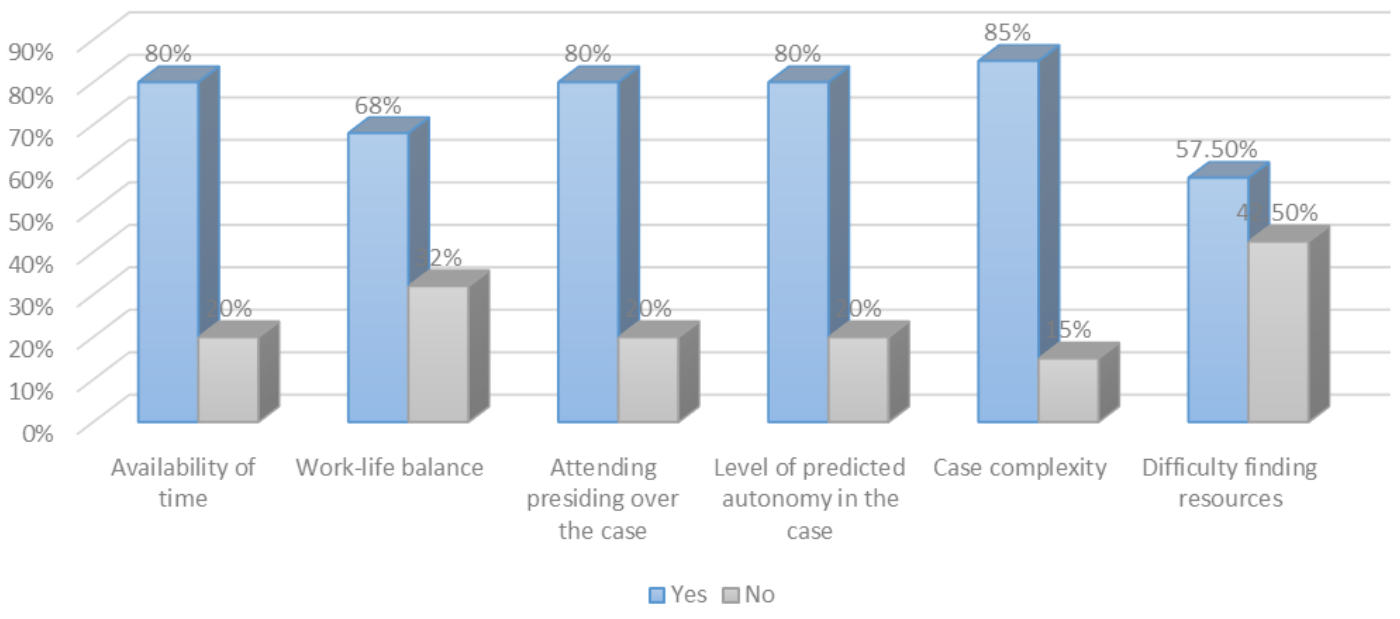

Figure 3. Factors Affecting Operating Room Preparation

\section{$4 \quad$ Resource Specific Use}

A number of resources are utilized by the trainees for preparation purposes. Keeping in mind the recent advances that have been incorporated into the surgical training, for example hands-on skills stations and virtual reality training suites that have been developed in the teaching hospitals, trainees were found to be aware of the availability of such resources. Eighty percent of the trainees noted that simulations were only helpful to learn a particular skill or practice, but these did not help them with any particular procedure. The majority of residents $(87.5 \%)$ were of the view that they use a particular resource to learn a skill or go through procedural details, like an atlas or a book, which may be helpful to learn a procedural detail but not acquire the skill. A group of trainees $(66.7 \%)$ was keen to attend the teaching sessions as they were more comfortable learning through this mode. 


\section{Resource specific use}

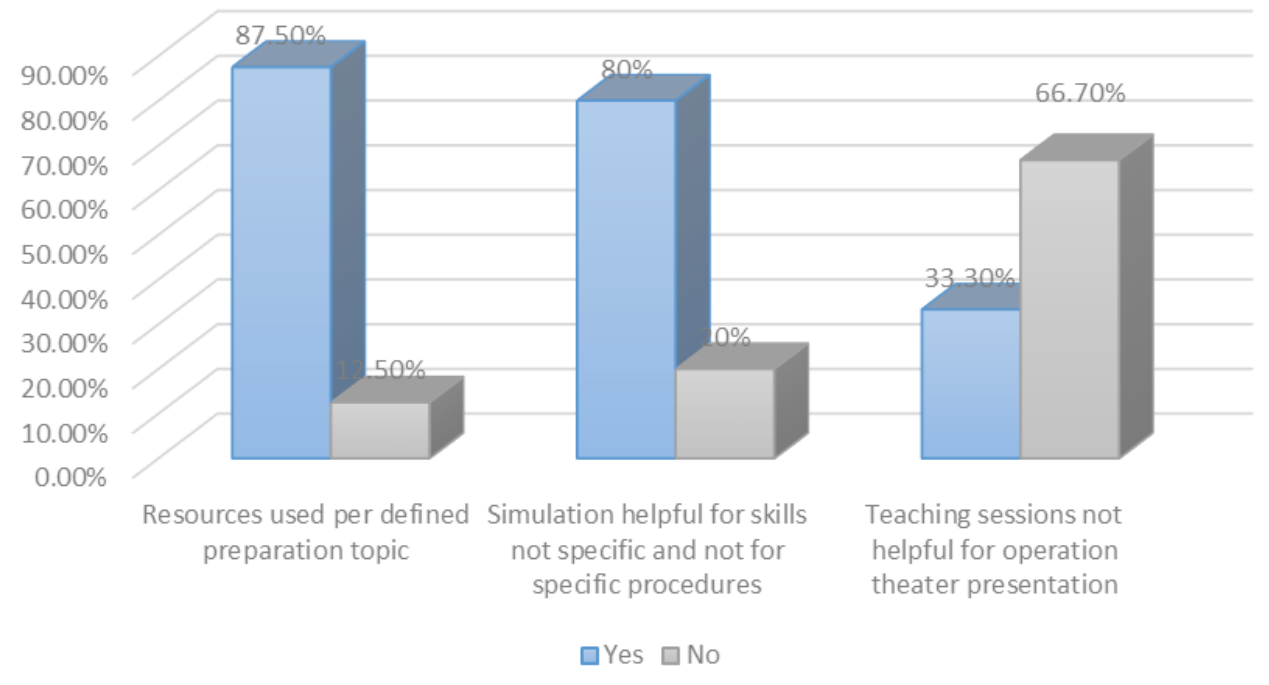

Figure 4. Resource specific use

\section{Difference in Preparation throughout Progression}

Trainees were asked if their preparation had changed throughout progression. Ninety percent of trainees were comfortable mentioning that the choice of resources and of alternate learning methods had changed over time as they progressed in their residency. Experience gained with time has also improved their approach towards preparing for cases. 


\section{Difference in preparation by PGY level}

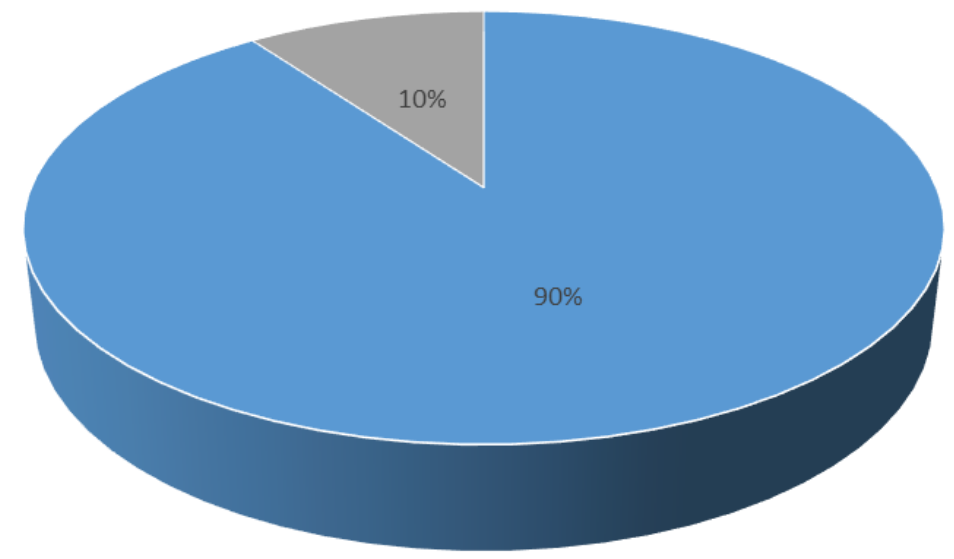

- Yes - No

Figure 5. Difference in preparation by PGY level

$6 \quad$ How do you Prepare/Study for Operating Room List?

A number of resources are available. However, out of available options, three genres of resources were preferred by the residents and were included in our survey. Of these, junior residents were found to be more comfortable utilizing video content for preparation. On the other hand, senior residents were utilizing review books and current literature to a notable extent.

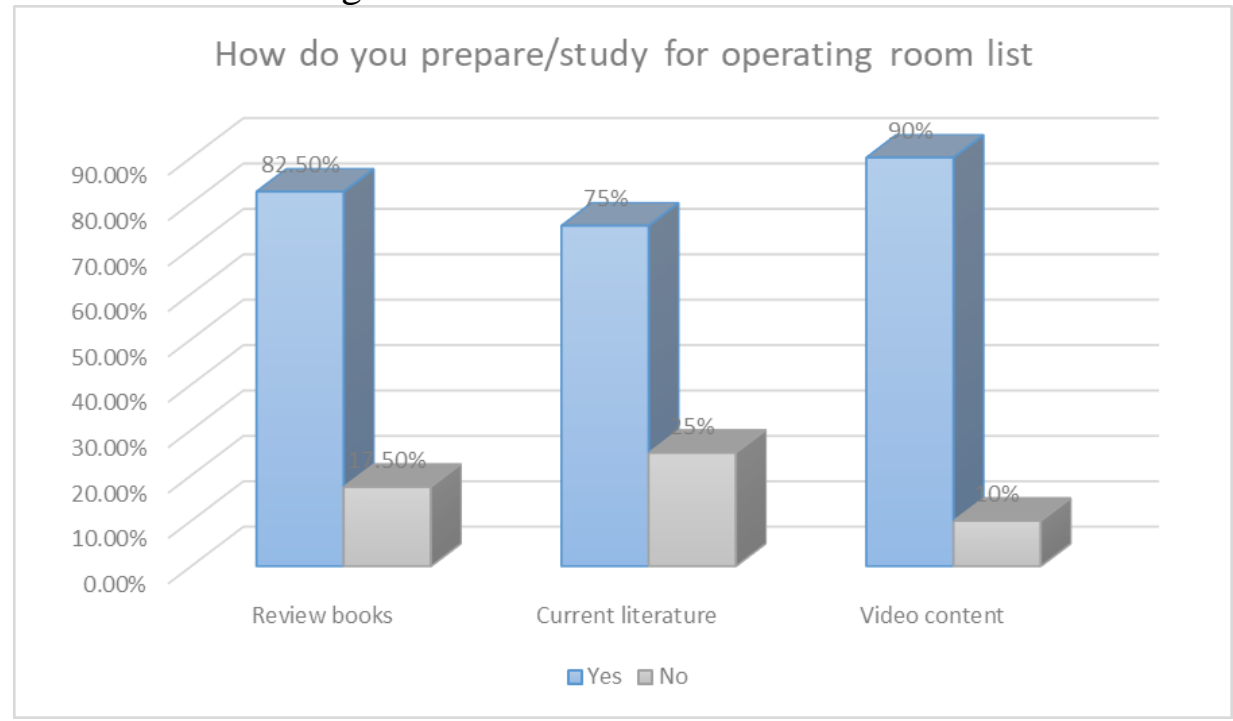

Figure 6. How do you prepare/study for operating room list 


\section{$7 \quad$ Guide to Preparation}

A trainee without a guide is more likely to end up a disaster while performing a procedure. They always take advantage of advice or help from a person scrubbed in with them. Fifty five percent of the residents were comfortable asking for guidance by a senior level resident with the majority belonging to junior Postgraduate level. Around forty percent were content going through the specifics with the attending during or prior to the procedure.

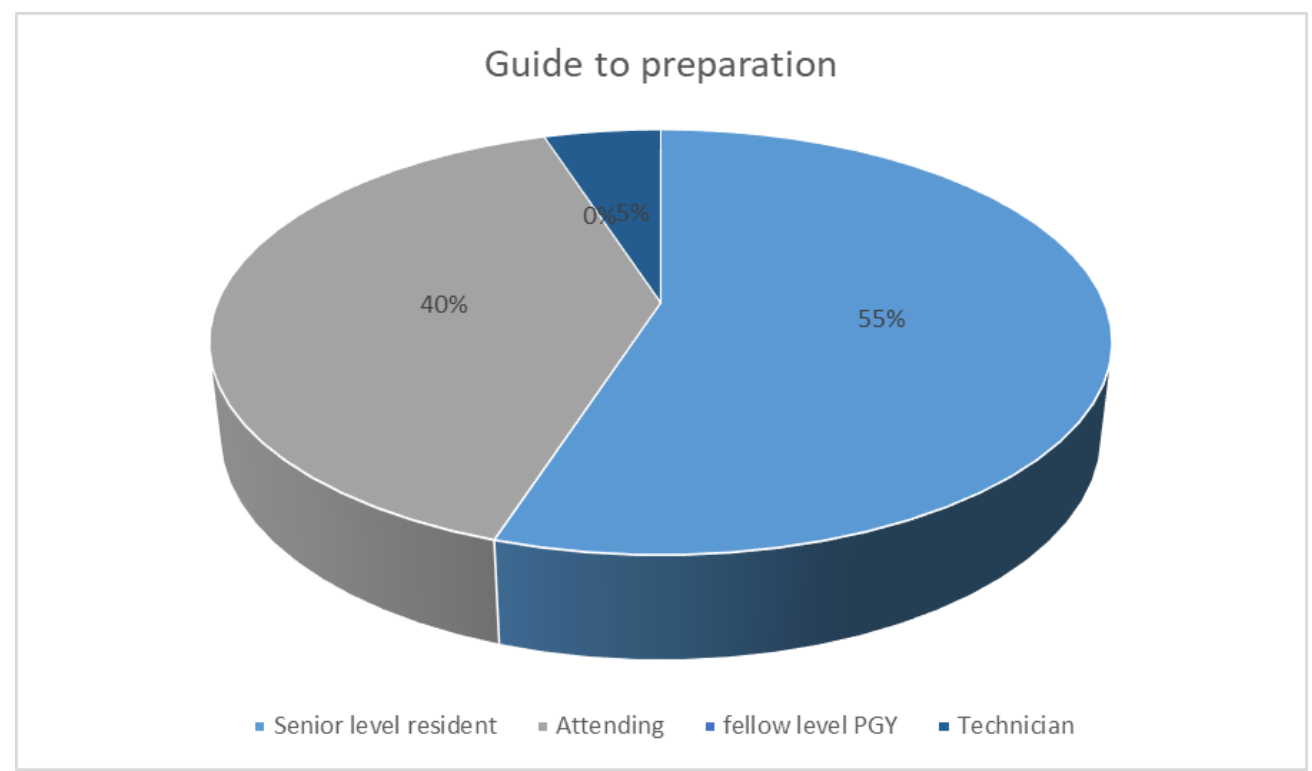

Figure 7. Guide to preparation

\section{$8 \quad$ Teaching Colleagues Aids in Preparation}

Teaching is a skill that is beneficial for both the teacher and the recipient. Whether it is a matter of learning a skill or going through the details of a specific disease, $87.5 \%$ of trainees were of the view that teaching undergraduate level students of junior colleagues aided in the preparation of the operation room list during the training time period. 


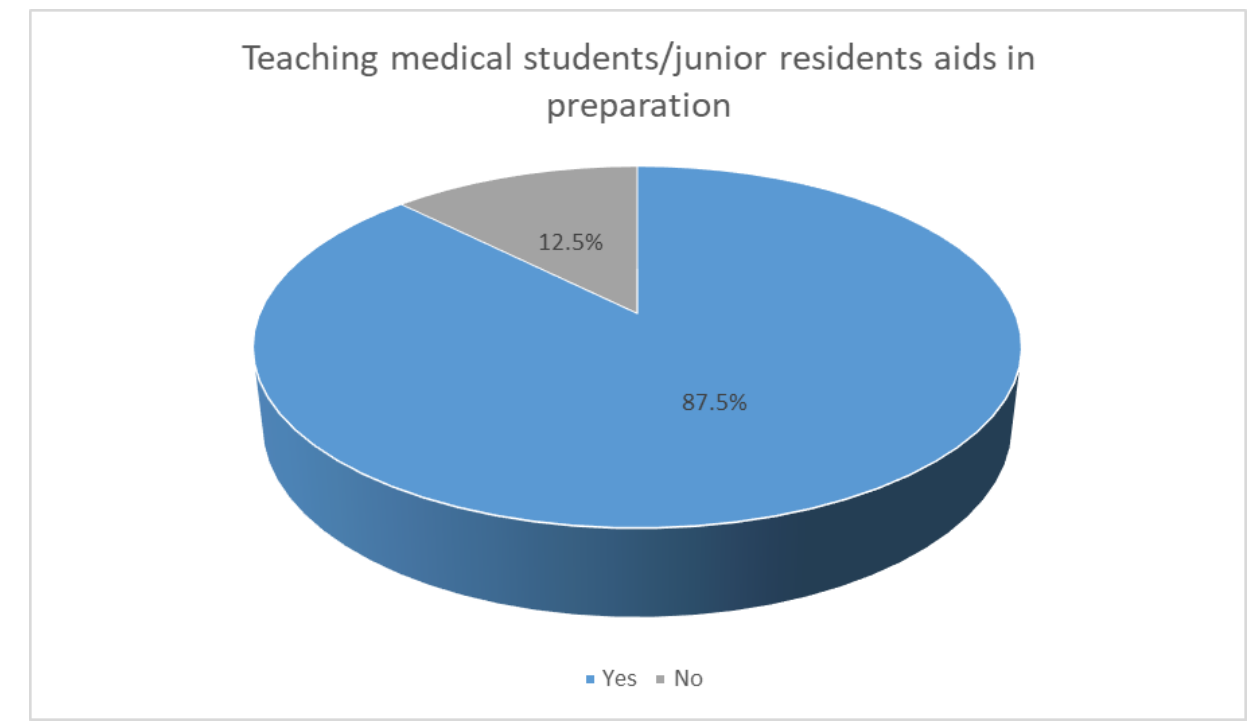

Figure 8. Teaching medical students/junior residents aids in preparation

\section{$9 \quad$ Optimal Resource in your Opinion}

Whatever resource was employed by the trainees for preparation, whether video content, review of books or current literature, it was defined by the residents that it should be clear, comprehensive, and concise. Easy availability and being inexpensive were other factors opted by the residents.

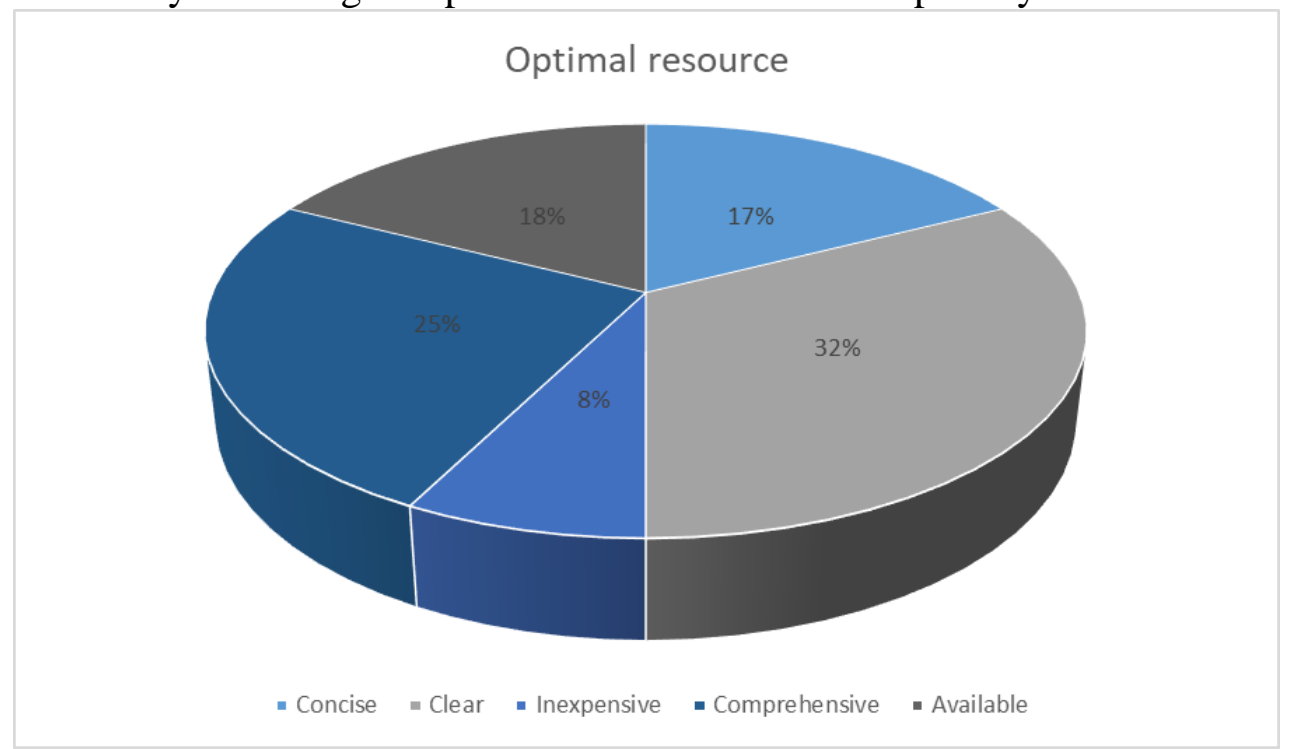

Figure 9. Optimal resource

\section{Discussion}

Surgical trainee's knowledge, attitudes, and practice towards operating room preparation were alike in some aspects, while they may vary in others. 
We found that the majority of trainees had a consensus about what they should know for the operating room case/list. Their preparedness was found to be affected by a number of variables including, largely, the availability of adequate quality time. Utilization of this quality time to prepare for the operation room is in itself affected by a number of factors, such as maintaining a decent balance between professional life \& family, availability of appropriate supervision while practicing skills such as virtual reality \& hands on skills, and in some cases a healthy discussion regarding the OR case/list with the attending. A large proportion of trainees pointed out that case complexity and predicted autonomy in the case also affected their preparation, for which they utilized variable resources as per availability and fastidiousness (Meyerson et al., 2017; Pernar et al., 2011). Many of them utilized video content and reviewed books, while senior trainees preferred current literature (Mundschenk et al., 2018). According to Archibald et al. (2014), incorporation of technology such as an iPad can help in teaching and learning, although need for further and more extensive studies was found to be deficient. The literature review showed that video demonstrations and lectures are excellent tools in learning skills and are trusted by both medical professionals and students (Lee et al., 2017; Jowett et al., 2007; Dinscore \& Andres, 2010; Clay, 2011; Xeroulis et al., 2007; Lenchus et al., 2011; Hansen et al., 2011). Knowing about the particular practices and similitude of a particular attending for a particular case affected preparation. Some felt this helped them gain the confidence of the trainer which resulted in acquiring more hands on work. This factor is one of many found through our survey and literature review and it plays a significant role in the allocation of desired autonomy to a surgical trainee.

Simulation-based learning is now the part of routine surgical training. While it may be helpful in developing skills, it may not enhance procedural competence completely. Similarly, teaching sessions are helpful for procedural details but cannot help in developing skills or replacing the virtual reality-based development of surgical skills. In short, both should go hand in hand. Simulation-based learning has an important role but these are inadequate without a procedure specific knowledge (Aggarwal et al., 2007; Kneebone et al., 2004).

Through our survey among the surgical trainees and as per the literature, it is clear that their preparation changes over time as they progressed in their surgical training, and learning through trial \& error with advice from a senior resident, is of utmost importance in the training period and after training from a colleague (Mundschenk et al., 2018). Trainees learn skills and procedures step by step with a portion of it learned in year one of training, while progressing to complete knowledge of it until the final year of training. Therefore, this points towards the implementation of a standard curriculum for 
all, such as SCORE curriculum, to be followed during the training in all training institutes (Bell, 2007). Currently guidance for training a trainee is either from attending under whom he/she is working with or a senior level resident.

Although a number of resources are utilized for learning, common characteristics for the optimal resource is that they should be clear, concise, easily available, and comprehensive (Goldwag \& Jung, 2020). This can either be a review book, lecture notes, simulation videos, actual procedural videos or online research-based literature. All resources with above mentioned characteristics work best when incorporated together, completing the jigsaw puzzle with all pieces put together in the designated sequence.

This study was done on a small number of participants working at a single institution which are limitations to be mentioned. Keeping in mind that a very few number of studies have been done on this topic, this study will add to literature for future larger scale studies or a meta-analysis. Another limitation was that the researcher did not meet the trainees personally and so the probability that there might be some misunderstanding in answering the questions may provide a bias. However, to mitigate this effect, the questionnaire was designed in a simple language which is easily understandable. All questions were close ended to yield authentic and precise results.

Since this study is done in a poor resource country with a weak educational system, there might be possibility of differences among other countries in terms of availability and utilization of resources. We hope that further large scale studies will be conducted in the future to know more about the factors that affect trainee preparedness and what are their needs to excel during the training time period.

\section{Conclusion}

Through our study, we demonstrated that the level of knowledge among trainees was nearly comparable, but their attitude towards preparation was variable and was found to be multi-factorial. They used a variety of resources for practicing and mastering the skills. Results yielded a wide array of materials being utilized for operating room preparation with differences noted as the trainees progressed in their training, but without any guidance except for a crucial role played by a senior colleague. They face a serious challenge due to shortage of time and unavailability of resources. This brings to attention that there must be a pre-defined curriculum for surgical training to guide both the attending and the trainee. 


\section{References:}

1. Aggarwal, R., Grantcharov, T. P., \&Darzi, A. (2007). Framework for systematic training and assessment of technical skills. Journal of the American College of Surgeons, 204(4), 697-705.

2. Archibald, D., Macdonald, C. J., Plante, J., Hogue, R. J., \&Fiallos, J. (2014). Residents' and preceptors' perceptions of the use of the iPad for clinical teaching in a family medicine residency program. $B M C$ medical education, 14(1), 174.

3. Bell, R. H. (2007). Surgical council on resident education: a new organization devoted to graduate surgical education. Journal of the American College of Surgeons, 204(3), 341-346.

4. Clay, C. A. (2011). Exploring the use of mobile technologies for the acquisition of clinical skills. Nurse education today, 31(6), 582-586.

5. Damewood, R. B., Blair, P. G., Park, Y. S., Lupi, L. K., Newman, R. W., \& Sachdeva, A. K. (2017). "Taking training to the next level": the American College of surgeons committee on residency training survey. Journal of surgical education, 74(6), e95-e105.

6. Dinscore, A., \& Andres, A. (2010). Surgical videos online: a survey of prominent sources and future trends. Medical reference services quarterly, 29(1), 10-27.

7. Evans, C. H., \& Schenarts, K. D. (2016). Evolving educational techniques in surgical training. Surgical Clinics, 96(1), 71-88.

8. Glass, N. E., Kulaylat, A. N., Zheng, F., Glarner, C. E., Economopoulos, K. P., Hamed, O. H., ... \& Winfield, R. D. (2015). A national survey of educational resources utilized by the Resident and Associate Society of the American College of Surgeons membership. The American Journal of Surgery, 209(1), 59-64.

9. Goldwag, J. L., \& Jung, S. (2020). Operating room preparation by general surgery residents: A qualitative analysis. The American Journal of Surgery, 220(2), 316-321.

10. Hansen, M., Oosthuizen, G., Windsor, J., Doherty, I., Greig, S., McHardy, K., \& McCann, L. (2011). Enhancement of medical interns' levels of clinical skills competence and self-confidence levels via video iPods: pilot randomized controlled trial. Journal of medical Internet research, 13(1), e29.

11. Holcomb, J. B., Dumire, R. D., Crommett, J. W., Stamateris, C. E., Fagert, M. A., Cleveland, J. A., ... \& Aoki, N. (2002). Evaluation of trauma team performance using an advanced human patient simulator for resuscitation training. Journal of Trauma and Acute Care Surgery, 52(6), 1078-1086.

12. Jowett, N., LeBlanc, V., Xeroulis, G., MacRae, H., \&Dubrowski, A. (2007). Surgical skill acquisition with self-directed practice using 
computer-based video training. The American Journal of Surgery, 193(2), 237-242.

13. Kneebone, R. L., Scott, W., Darzi, A., \& Horrocks, M. (2004). Simulation and clinical practice: strengthening the relationship. Medical education, 38(10), 1095-1102.

14. Lee, J. C., Boyd, R., \& Stuart, P. (2007). Randomized controlled trial of an instructional DVD for clinical skills teaching. Emergency Medicine Australasia, 19(3), 241-245.

15. Lenchus, J., Issenberg, S. B., Murphy, D., Everett-Thomas, R., Erben, L., Arheart, K., \& Birnbach, D. J. (2011). A blended approach to invasive bedside procedural instruction. Medical teacher, 33(2), 116123.

16. Lobo, M. J., Crandley, E. F., Rumph, J. S., Kirk, S. E., Dunlap, N. E., Rahimi, A. S., ... \& Read, P. W. (2013). Pilot study of iPad incorporation into graduate medical education. Journal of graduate medical education, 5(1), 142-144.

17. Meyerson, S. L., Sternbach, J. M., Zwischenberger, J. B., \& Bender, E. M. (2017). Resident autonomy in the operating room: expectations versus reality. The Annals of thoracic surgery, 104(3), 1062-1068.

18. Mundschenk, M. B., Odom, E. B., Ghosh, T. D., Kleiber, G. M., Yee, A., Patel, K. B., ... \& Buck II, D. W. (2018). Are residents prepared for surgical cases? Implications in patient safety and education. Journal of surgical education, 75(2), 403-408.

19. Pernar, L. I., Breen, E., Ashley, S. W., \& Peyre, S. E. (2011). Preoperative learning goals set by surgical residents and faculty. Journal of Surgical Research, 170(1), 1-5.

20. Pugh, C. M., DaRosa, D. A., Glenn, D., \& Bell Jr, R. H. (2007). A comparison of faculty and resident perception of resident learning needs in the operating room. Journal of Surgical Education, 64(5), 250-255.

21. Scott, D. J., \& Dunnington, G. L. (2008). The new ACS/APDS skills curriculum: moving the learning curve out of the operating room. Journal of Gastrointestinal Surgery, 12(2), 213-221.

22. Seymour, N. E., Gallagher, A. G., Roman, S. A., O'brien, M. K., Bansal, V. K., Andersen, D. K., \& Satava, R. M. (2002). Virtual reality training improves operating room performance: results of a randomized, double-blinded study. Annals of surgery, 236(4), 458.

23. Sturm, L. P., Windsor, J. A., Cosman, P. H., Cregan, P., Hewett, P. J., \&Maddern, G. J. (2008). A systematic review of skills transfer after surgical simulation training. Annals of surgery, 248(2), 166-179.

24. Xeroulis, G. J., Park, J., Moulton, C. A., Reznick, R. K., LeBlanc, V., \&Dubrowski, A. (2007). Teaching suturing and knot-tying skills to 
medical students: a randomized controlled study comparing computerbased video instruction and (concurrent and summary) expert feedback. Surgery, 141(4), 442-449.

25. Yeo, H., Viola, K., Berg, D., Lin, Z., Nunez-Smith, M., Cammann, C., ...\& Curry, L. A. (2009). Attitudes, training experiences, and professional expectations of US general surgery residents: a national survey. Jama, 302(12), 1301-1308. 